\title{
El ojo de las Grayas: compromiso y alteridad en tres poetas venezolanas de los años noventa
}

\author{
José Antonio PANIAGUA GARCÍA \\ Universidad de Salamanca \\ jantopagar@usal.es
}

\begin{abstract}
RESUMEN
Este trabajo analiza, en el contexto venezolano de crisis sociocultural y descreimiento político-económico de los años noventa, tres poemarios de singular relevancia en la producción literaria escrita por mujeres: El arte de la pérdida (1991) de Verónica Jaffé, Olympia (1992) de Manón Kübler y Safari Club (1993) de Laura Cracco. Una lectura de estas obras a partir de las nociones de compromiso y alteridad nos permitirá observar dichos referentes de la eclosión femenina como modelos alternativos de responsabilidad en un diálogo abierto con la vieja literatura nacional. Desde este planteamiento, además de aproximarnos hacia inéditas reflexiones sobre el Otro, confirmaremos en ellos la aportación de originales y transgresoras representaciones de frontera, género, sexualidad, imaginación histórica y memoria colectiva que nos llevarán, en última instancia, a plantear nuevos interrogantes sobre la historia literaria de Venezuela.
\end{abstract}

Palabras clave: poesía venezolana, años noventa, mujer, alteridad, compromiso.

\begin{abstract}
This paper analyzes, from the social and economic crisis in Venezuela and the unbelief with the alternative political programs in the nineties, three remarkable books of poems in the literary production written by women: El arte de la pérdida (1991) by Verónica Jaffé, Olympia (1992) by Manón Kübler and Safari Club (1993) by Laura Cracco. Through the notions of alterity and engagement, these works take over new prototypes of responsibility in dialogue with the old national literature. From this perspective, besides an approximation to innovative kinds of reflections about the Other, these poetics have provided original and transgressive representations of borders, gender, sexuality, historical imagination and collective memory that raise new questions about literary history of Venezuela.
\end{abstract}

Keywords: Venezuelan poetry, nineties, woman, alterity, engagement.

Sumario: 1. Mujer, compromiso y alteridad: un modelo crítico, 2. El ojo de las Grayas: tres poetas venezolanas, 3 . Hacia nuevos paradigmas. 
La década de los setenta del siglo XX señala un hito fundamental de la poesía venezolana. Por un lado, la literatura asumirá una cierta sincronía con el arte europeo, fruto del auge económico, la apertura hacia nuevos discursos y una intensa labor de traducción y publicación de autores foráneos. De manera aún más insólita, en estos años dará comienzo un proceso literario que culminará en la década posterior y que conocemos con el nombre de eclosión femenina, inserto en un debate mayor sobre los imaginarios establecidos en la cultura. Estos diálogos permitirán a las escritoras, habitualmente marginalizadas, encontrar una voz para cuestionar desde la sentimentalidad y el eco social las falacias de la tradición.

La eclosión femenina, que adquiere su especificidad tras la integración de la mujer en diversos sectores y la reforma del Código Civil, alentará la recuperación de algunos recursos realistas de los años sesenta e incorporará la variable de género como rasgo diferenciador ${ }^{1}$. A pesar de ello, el contexto finisecular venezolano, marcado por la crisis financiera, el populismo y la espectacularidad del Estado y el descreimiento con los programas alternativos, estrechará los lazos entre intelectuales, artistas e instituciones, al mismo tiempo que reducirá el espacio social a una dimensión que debe resistir el peso de todas las ilusiones frustradas. En el plano formal, se rehuirán la sentimentalidad, la brevedad y la cotidianidad como pautas de indagación predominantes y se apostará por una poesía culturalista, ligada a los referentes históricos ${ }^{2}$.

Debido a esta coyuntura, el escritor Salvador Garmendia, en los umbrales del segundo milenio, diagnosticará el fin del compromiso literario, circunstancia que se habría desarrollado sin grandes declaraciones de clausura desde la década de los setenta $^{3}$. No obstante, algunas características como la depuración de elementos paródicos y la «desaparición de las máscaras y ritualizaciones del cuerpo» en estas poéticas apuntan, por el contrario, a una voluntad de desnudar la voz lírica para indagar en lo propio, procedimiento orientado hacia una colectividad que depende en gran medida de nuestra idea del otro ${ }^{4}$. Esta ponderación, lejos de ratificar el testimonio de Garmendia, advierte de la necesidad de ahondar en el debate sobre el compromiso en los dos últimos decenios del siglo XX.

\section{Mujer, compromiso y alteridad: un modelo crítico}

Uno de los grandes descuidos a la hora de afrontar la literatura escrita por mujeres es su homogeneización en una línea de creación universal que se desentiende del contexto y marca las pautas de conocimiento del mundo y los límites de sus proce-

${ }^{1}$ Y. Patin y A. T. Torres (2003), pp. 105-106; M. A. Pérez López (2005), pp. 369-371.

2 J. Lasarte Valcárcel (1999), pp. 282-283; M. Gomes (2003); L. Álvarez (1998), p. 42.

${ }^{3}$ S. Garmendia (1999).

${ }^{4}$ Y. Patin y A. T. Torres (2003), p. 126; V. Jaffé (1999), p. 330. 
sos de representación, lo que cristaliza esta producción en un canon absoluto ${ }^{5}$. La crítica venezolana, en general, ha optado por la lectura segregada de los textos para restablecerlos más tarde dentro del patrimonio literario global; en particular, además, ha destacado como su propiedad más reconocible el nexo de estas autoras con el cuerpo, lo que nos permite concluir que lo orgánico actúa en ellas como el sustento social y cultural de una voz que enuncia desde la interioridad pero que se proyecta hacia lo que está fuera ${ }^{6}$.

En primer lugar, este aspecto guarda una estrecha relación con una observación tradicional sobre la literatura escrita por hombres: su inherente universalidad. A este respecto, con independencia de las conductas y su grado de radicalidad, se ha señalado en el discurso de las escritoras una tendencia a la compensación, consistente en el uso de mecanismos desestabilizadores de su herencia literaria, pero acometidos con una disposición que pretende escapar del compromiso, favoreciendo un distanciamiento e incluso una renegación de esta postura ${ }^{7}$. Sin embargo, este recurso no es inocuo. La aparente ausencia de compromiso puede estimarse como una herramienta de resistencia política por su denuncia de la imitación y su alejamiento simultáneo del objeto imitado (lo que Reisz llama una "poética plagiaria») ${ }^{8}$. Asimismo, la acusada falta de universalidad no obstaculiza la vinculación de las obras con la representación de sectores marginalizados, prestándoles una «voz plural y pública» que abre el camino de la responsabilidad con el Otro?.

En segundo lugar, debemos insistir en la frecuencia con la que el compromiso ha sido reconocido en exclusiva como definición subjetiva e histórica de la idea de Estado, discriminando así la discusión sobre la individualidad. De este modo, la crítica ha reducido sus propiedades a los rasgos explícitos de la enunciación y a su posibilidad de descodificación en función de un «sistema de convenciones comunicativas» que niega interés alguno a su lógica interna ${ }^{10}$. Frente a esta perspectiva, Bernal Herrera identifica el compromiso por la presencia de dos atributos: una temática que emane de la realidad social y que a su vez esté considerada como un motivo de conflicto en el horizonte de debate y, por otro lado, la adopción de una posición reconocible por parte del autor. Esta hipótesis, que muestra su flaqueza en la necesidad del consenso para discriminar el grado de implicación, puede sernos, en cambio, de enorme utilidad a la hora de sugerir un criterio metodológico operativo del compromiso ${ }^{11}$.

5 B. González Stephan (1990), pp. 83-84; A. López Ortega (2004), p. 114; J. Miranda (1995), p. 19; J. Rodríguez Padrón (2009), p. 16;

${ }^{6}$ B. Pacheco (2006), pp. 821-825; J. Miranda (1995), p. 27; G. Zambrano (2000), p. 89.

${ }^{7}$ S. Reisz (1996), pp. 45-46.

${ }^{8}$ S. Reisz (1996), p. 56.

${ }^{9}$ S. Reisz (1996), pp. 29; B. González Stephan (1990), p. 92.

${ }^{10}$ J. C. Rodríguez (2002), pp. 54-56; R. Pring-Mill (1992), p. 36-40.

${ }^{11}$ B. Herrera (2002), pp. 8-9 y 18. 
Para ello, se vuelve imprescindible señalar, a nivel epistemológico, el curso paulatino, a partir de los años ochenta y toda la década de los noventa, de cambios políticosociales, económicos y culturales que se sucederán con asombrosa rapidez; una profusión de acontecimientos que deriva en la pérdida de la inteligibilidad del tiempo, la consecución del espacio como una dimensión inaprensible y la superabundancia del ego, que se somete a la historia colectiva, fluctuante e inestable. Todas estas singularidades, señaladas por Marc Augé en su trabajo sobre los «no lugares», además de cuestionar los esquemas simbólicos, favorecieron el surgimiento de un arte aparentemente apolítico, fruto de la transterritorialidad que conlleva la incapacidad de integración en los procesos globales ${ }^{12}$. Esta dinámica de superposición, por consiguiente, motivará el estallido de inusitadas experiencias de soledad y desamparo y un repliegue del individuo sobre sí mismo que da como resultado la huida, el miedo y la rebelión ${ }^{13}$. En consecuencia, juzgar la eclosión femenina como un alejamiento del compromiso de una poesía que aspiraba a lo absoluto nos obligaría a plantear nuevas lecturas fundamentadas en la experimentación de la contemporaneidad ${ }^{14}$; en particular, será necesario indagar en la relación del individuo con su alteridad.

Una rápida ojeada por la historia de la literatura revela que el papel de la mujer ha estado marcado por la utilización de identidades impostadas para ocultar su naturaleza biológica, lo que nos impide concebir su participación en el arte de modo unidimensional o natural ${ }^{15}$. Su labor, por tanto, remite a un deseo de traducir la escritura como establecimiento de una relación entre el yo y el Otro que supere las dialécticas preexistentes. Antes de llegar a un flujo lingüístico y simbólico de dominación, del cual proyectan escabullirse, una serie de cuestionamientos éticos, fundados, en su mayoría, en la corporalidad, frenan el perjuicio o la marginación del sujeto, lo cual encarna un modelo de compromiso evidente. Así, tras el colapso semiótico del Otro, infinitamente separado del Yo y ausente de todo lugar, propio de la tradición filosófica, la alteridad comienza a considerar que la representación es una fase límite del compromiso con la realidad, de tal suerte que existiría alguna especie de fracaso, desengaño o desestructuración de una materialidad que solo encuentra su terminación en la representación misma $^{16}$.

Desde este planteamiento, lo representado adquiere una responsabilidad ética con la visibilización de realidades desplazadas, de manera que en la eventualidad del enunciado, el lenguaje se desactiva como sustentador de la retórica opresora. En la concomitancia del sujeto con su entorno, aquel reconoce en el Otro su autoridad superior, en

\footnotetext{
${ }^{12}$ M. Augé (1998), pp. 30-47; M. Gomes (2003), pp. 257-258.

${ }^{13}$ M. Augé (1998), pp. 97-112.

${ }^{14}$ Y. Patin y A. T. Torres (2003), p. 108; R. Pring-Mill (1992), p. 42; M. Augé (1998), p. 26; A. López Ortega (1995), p. 33.

${ }^{15}$ M. Russotto (2004), p.66.

${ }^{16}$ E. Lévinas (2012), pp. 187-190; M. Gomes (2003), p. 265.
} 
efecto, pero esto obedece a una asunción de fragilidad y finitud. Es en esta búsqueda en la cual se revela la «carencia» del Yo (su imposibilidad de constituirse en la exclusión), lo que activa el mecanismo de apelación ${ }^{17}$. Para explicar la función de la alteridad en estas poéticas, además, tenemos que aceptar que existe en el plano de la fenomenología una serie de experiencias que remiten a un grado variable de pasividad, pues de lo contrario la interpelación y la ausencia no podrían concebirse ${ }^{18}$. Por tanto, no es de extrañar que las poetas de la eclosión femenina apuesten por una línea de creación que relaciona el Eros con el vacío y el requerimiento, pues «por la sexualidad el sujeto entre en relación con lo que es absolutamente otro: con una alteridad de tipo imprevisible en la lógica formal, con lo que permanece otro en la relación sin convertirse nunca en mío» ${ }^{19}$.

La fabricación de la identidad a través de máscaras y voces simuladas describe un erotismo alejado de la estructura dialéctica que ha impedido a la mujer autorepresentarse y gozar de cualquier placer específicamente suyo ${ }^{20}$. Este concepto de identidad múltiple acerca al individuo la posibilidad de reactualizarse, lo que configura una alteridad más rica en sus lecturas al construirse en función del contexto del cual sus propias representaciones son herederas. La responsabilidad de estas poéticas, en conclusión, ordenaría el compromiso «como algo que debe institucionalizarse, pues es valioso en sí mismo y con pretensiones de universalidad», integridad que enfrenta los propósitos de un discurso que las poetas de la eclosión femenina han ansiado neutrali$\operatorname{zar}^{21}$.

\section{El ojo de las Grayas: tres poetas venezolanas}

Tres, cygniformes, con un ojo solo $Y$ un solo diente, habitan, ni reciben La luz del sol, ni de la tibia luna.

Esquilo

\footnotetext{
${ }^{17}$ E. Lévinas (2012), p. 70; P. Ricoeur (1996), p. 200. Debe advertirse en este punto que el concepto de alteridad es manejado en este trabajo evitando entrar en una discusión crítica que nos alejaría del propósito inicial de esbozar un primer acercamiento a la poesía venezolana de la eclosión femenina con ojos nuevos, de ahí que se tomen exclusivamente, en un ejercicio de simplificación, los elementos que pueden sernos de utilidad para tal fin. Sin embargo, parece pertinente sugerir aquí la necesidad de una mayor cautela en cuanto al concepto de Lévinas sobre la ética, ya que su hipótesis favorece en extremo la desaparición del contorno autónomo del Yo y reduce su naturaleza a una visión esencialista. P. Ricoeur (1996), pp. 373-374; O. Fernández Guerrero (2012), p. 299.

${ }^{18}$ P. Ricoeur (1996), p. 352.

${ }^{19}$ E. Lévinas (2012), p. 313.

${ }^{20}$ R. Castillo Zapata (1994), p. 371; T. Moi (1988), p. 144.

${ }^{21}$ O. Fernández Guerrero (2012), pp. 310-314; M. Augé (1998), p. 26.
} 
La tensión que marcó las relaciones entre tradición y modernidad en la primera mitad del siglo XX ofreció a las escritoras venezolanas la oportunidad de inspeccionar una poética más amplia. Su ubicación en estos conflictos les habilitó para experimentar con la sensibilidad y la subjetividad desde la omisión de dogmas y militancias, estableciendo en lo fundante, alejado del orden histórico, una relación orgánica con el mundo y la memoria ${ }^{22}$. De la evolución de estos condicionamientos, nacerán en los años noventa tres poemarios: El arte de la pérdida (1991), de Verónica Jaffé; Olympia (1992), de Manón Kübler y Safari Club (1993), de una ya consolidada Laura Cracco. Estas tres obras, por lo demás divergentes entre sí, tienen en común su decidido compromiso con una alteridad dispuesta a «la apertura del poema a territorios inéditos, la desacralización tanto de la figura del poeta como de la poesía misma, [y] la consideración y atención a aspectos menores o poco tratados de la reali$\operatorname{dad} \gg{ }^{23}$.

Si concretamos estos breves apuntes en la producción de Verónica Jaffé, nos encontraremos ante una de las autoras que ha profundizado con mayor hondura en la extranjeridad y en el dolor de las identidades fracturadas, a través de la memoria de un referente que impide determinar en la escritura la voz lírica. En su poética es el lenguaje del Otro el que nos define, y su ausencia, en último término, lo que suscita la evocación de la carencia, empujada por la rivalidad con la cultura ${ }^{24}$ :

El idioma no suena al oído.

El paseante se siente extranjero, las casas de techos cargados de rocas parecen vacías.

La ausencia se esconde en sus ojos, en el calor del abrigo de lana.

En soledad se sueña el paseante, murmura el nombre, los nombres de algunas personas que antes le dieron su mano y su beso, recita: oh solitude, my sweetest price ${ }^{25}$.

\footnotetext{
${ }^{22}$ M. Russotto (1995), pp. 151-154; J. Rodríguez Padrón (2009), p. 20.

${ }^{23}$ Y. Pantin (1999), p. 312; A. López Ortega (1995), p. 27.

${ }^{24}$ Y. Patin (1999), p. 315; A. López Ortega (2004), pp. 116-117; Y. Patin y A. T. Torres (2003), p. 131.

${ }^{25}$ V. Jaffé (1991), p. 45.
} 
La privación del Otro mantiene en Jaffé una estrecha conexión con dos motivos: la historia de los crímenes nazis y el erotismo que encuentra en los márgenes de la expresión su goce más pleno. Dicha alianza revela una intensa labor de universalización de estos procesos como parte de un sentimiento global que requiere de la responsabilidad del ser para no sobrepasar los límites de la ética. Este relato se construye a partir de la imagen de una niña impotente ante el desmoronamiento de su infancia, lo cual permite dilatar el miedo como un signo generacional ${ }^{26}$ :

$[\ldots]$ en tus brazos niña sueñan los inumerables fieros caballeros del apocalipsis cruces gamadas sobre el pecho persiguiendo lo innombrable lágrimas de noche miedo niña duerme y descansa huye luego en la mañana de los hombres ${ }^{27}$.

Una de las principales apreciaciones de Lévinas sobre la pérdida asegura que el recuerdo se reafirma en la búsqueda de un tiempo que ya expiró, pretensión que fracasa mucho antes de su arranque y constata la imposibilidad de restituir lo extraviado. Esta poética lamenta, así, la dificultad para construir la individualidad desde la alteridad evocada, aunque a veces esta ayude a proyectar el Yo sobre la construcción de alegorías nacidas de los arquetipos culturales, como podemos observar en el poema titulado «Un fragmento del diálogo entre Ulises y Circe» ${ }^{28}$. Las relaciones sentimentales y el erotismo se interrogan por la situación del placer libidinal en los nuevos tiempos, una reflexión que debe leerse, también, en clave metaliteraria:

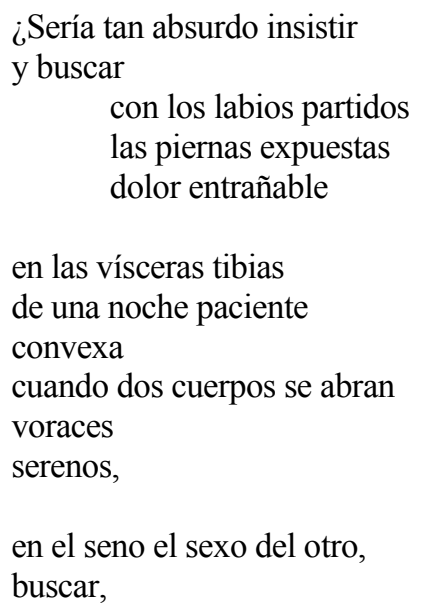

\footnotetext{
${ }^{26}$ J. Miranda (1995), pp. 229-230; R. Arráiz Lucca (2002), pp. 393-394.

${ }^{27}$ V. Jaffé (1991), p. 14.

${ }^{28}$ V. Jaffé (1991), p. 19. Vid. E. Lévinas (2012), p. 318; M. A. Pérez López (2005), p. 375.
} 
la encarnación

del placer absoluto ${ }^{29}$

Por su parte, Manón Kübler responde a este debate incorporando la homosexualidad femenina en las letras venezolanas. Su principal compromiso radica en el carácter existencial del poemario, que no propone miradas retrospectivas sino que funda una tradición propia hasta convertirla en lógica primordial. En el primer poema del libro leemos:

Hagamos usted y yo un largo viaje por la casa de los vivos. de esos ejemplares que, bien conservados preguntan de usted y de mí. hagamos un alto en el recorrido sobre su cama para sabernos vivas, que somos la parte parecida a las tormentosas rayas de la noche, las que no vemos, las que no probaremos nunca. deme usted la parte de su cuerpo, esa orilla que nadie conoce, ni siquiera las intimidades de su baño ni los pudores discretos de su espejo. quiero acostarme con usted a esta hora para saber que la tengo debajo de una mano, las rodillas en su riñón, su espalda repartida ${ }^{30}$.

Olympia manifiesta una conciencia de individualidad que se posiciona, ajena al miedo paralizante, en un lugar apartado de los flujos de dominación. Por consiguiente, el sujeto halla, contra al canto de la memoria, un espacio intersticial vigente que concreta una existencia feliz ${ }^{31}$. No obstante, marcado por la declaración violenta y el deseo bajo tortura, el Yo termina por alejarse del Otro, con lo cual su discurso se abandona al armazón de los significantes: la sola materia, que es lanzada con torrencialidad gracias a una sintaxis desprovista de puntuación. De esta forma, los poemas rebosan un hastío que emana de los paraísos artificiales donde el amor se contiene en su cualidad más efímera hasta la llegada de la insatisfacción y la desidia:

[...] quiere decir de mis horarios, de mis trastornos, de esta sola oportunidad de hablar en textos que se queman solos porque me representan y yo me siento singular y sola como un planeta, quiero decir esto, sin más, la reconstrucción estricta de mi voz manchando las paredes en un acto irrevocable de humildad, de desnudez, quiere decir nada, mi nada, la nada. la de esta edad. la del apartamento que no me gusta. la de mi almohada sosteniendo mi nuca para nadie, para esta sombra que hace peso, que me obliga a recorrer los escalones como quien viene perdido de una guerra para vivir o seguir muriendo en otra. la de los ausentes. ${ }^{32}$

${ }^{29}$ V. Jaffé (1991), p. 39.

${ }^{30}$ M. Kübler (1991), p. 15. Vid. F. Rodríguez, en M. Kübler (1991), p.11; J. Miranda (1995), pp. 279-280; L. Marcotrigiano (2002), pp. 25, 49; G. Zambrano (2004), p. 238; M. A. Pérez López (2005), p. 373.

${ }^{31}$ Y. Patin y A. T. Torres (2003), p. 130.

${ }^{32}$ M. Kübler (1991), p. 59. Vid. R. Arráiz Lucca (2002), p. 396; J. Miranda (1995), pp. 279280. 
Cuerpo y sexualidad desempeñan un papel contingente de inscripción del sujeto en la histórica política y social como garantes de una ilusión de monumentalidad que permite vivir el presente como materialidad y no como abstracción ${ }^{33}$. Desde esta perspectiva, el compromiso adquirido con la alteridad puede cifrarse en un compromiso con el deseo de pertenencia. Frente a una poesía escrita por mujeres como salvajes libertarias, la obra de Kübler va más allá de un estilo ensayado para romper con el molde de lo que el consenso dicta sobre los rígidos formatos de una escritura nacional. Su valor de subversión de códigos y subjetividades tendría su más aguda expresión en la parodia de sí misma y de los tópicos de la tradición: «afortunada de mí que pude regresar al trago de la mañana» ${ }^{34}$. Pese a ello, el viaje de su protagonista fracasa. El ya mencionado alejamiento del Otro impide transmitir cualquier sentido lógico a través del verbo negado a la voz de la mujer, extranjera de sí; la única posibilidad es trascender el mundo orgánico:

en la alta torre está la tártara. celos se recogen en su voz matinal. brevemente despliega las tímidas y amarillas voladuras, se cierra en un aplomado antojo de alpiste, no revuela, no se inquieta, solamente se repite ave, proverbio, pan. se acoda en las rejas y de tanto en tanto revela su tibia compañía, su destino de ángel, siempre apocalíptico, aroma del apio de los marzos. nada persigue. porque la letanía ha sido tapiada. voz acolchada, glacial, repique, que sólo enturbian las silenciosas y adorables escafandras donde las dos bajamos a los sótanos de nuestros miedos y nos damos la mano para atravesar. ${ }^{35}$

Un final semejante encontrarán los personajes de Safari Club, de Laura Cracco, un libro que reitera algunas de las líneas anunciadas en sus dos obras anteriores: Mustia memoria (1983) y Diario de una momia (1989). Yolanda Patin y Ana Teresa Torres, a propósito de la poesía venezolana de los noventa, comentan la capacidad de estas autoras para transmutar la heroicidad de la Historia en una estética de «destrucción, crueldad y carne muerta», en el caso de Cracco a través de la alegoría y la metáfora que encierran el mundo en una sala de baile ${ }^{36}$. En esta dimensión se dan cita todos los discursos existenciales, marcados por la sordidez y llevados hasta su extremo, para lo cual la memoria funciona como una pantalla que devuelve la imagen de lo residual del mundo, de su inmundicia, de lo parasitario de su fundación ${ }^{37}$. De este modo, Safari $C l u b$ nos muestra una serie de personajes o máscaras que relatan sus vivencias, marcadas en el caso de las mujeres por el castigo eterno de su condición improductiva en el

\footnotetext{
${ }^{33}$ M. Augé (1998), p. 65.

${ }^{34}$ M. Kübler (1991), p. 65. Vid, V. Jaffé (1999), pp. 331-332.

${ }^{35}$ M. Kübler (1991), p. 89.

${ }^{36}$ Y. Patin y A. T. Torres (2003), p. 129.

${ }^{37}$ J. Rodríguez Padrón (2009), pp. 26-27.
} 
espacio urbano, caracterizado por la esterilidad que culmina en una vida llevada al límite de su integridad:

Nací en una tierra impía, el sol escarba las membranas de la vida, reseca el embrión, cava tumbas en el útero de las mujeres huecas como cenotafios. Ella me hizo de polvo, de calor que fermenta y abre capullos vencidos, pare hijos del hastío, criaturas marcadas por la vegetación, alambre de púas hincado en el horizonte. Ella me vio nacer en parto violento, una luz igual a la más feroz puñalada abrió mis ojos, ciegos de resplandor. A los veinte años me vio morir bajo el azar que devora las entrañas y abandona a la tierra el cuero hinchado. ${ }^{38}$

En consecuencia, no solo debe reconocerse en Laura Cracco un compromiso con la alteridad de los sectores marginalizados por la historia, sino también un compromiso con la historia misma, con el descubrimiento y denuncia de las falacias que han sostenido un esquema androcéntrico que ha dictaminado la posición que le corresponde a la mujer, que ahora exhibe su voz comprometida: «Soy la rata que roe la fe y rasga la nada tan celosamente guardada, comí del cordero, mordí el pan, bebí del vino, nada asentó en mí, nada quedó de aquella cena» ${ }^{39}$. En cambio, otra de las cualidades señaladas por Lévinas, el derroche, advierte que en toda experiencia de lo humano reside una facultad inherente de apropiación de lo orgánico para hacerlo girar inútilmente en torno a nuestro propio goce, confirmando que «el mundo responde a un conjunto de finalidades autónomas que se ignoran las unas a las otras» ${ }^{40}$. En este sentido, la sexualidad, el erotismo o la comida pierden su valor de trascendencia y significación cuando borran su condición de necesidad en la rutina (la cursiva es mía):

Habito una ciudad llena de calles anónimas, pasamos sin dejar huella y los segundos resbalan sobre el pavimento. Hurgo en la tierra y no encuentro raíz, pertenezco a una raza en cuyo pasado aguarda la estatua de sal, la grieta de una sequía infinita, epílogo de una estirpe de mujeres que maduran a los once años, paren hijos de polvo. En mi pais no hay historia. ${ }^{41}$

A raíz de este último fragmento, parecería un error negar a Laura Cracco el compromiso con su contemporaneidad, en la cual la ciudad no concede ya oportunidades de construir el $\mathrm{Yo}^{42}$. Por tanto, al concluir su epopeya urbana, el poema desiste de su empeño y se propone abandonar el mundo material, simbolizado en la figura de dos pájaros suicidas; sin embargo, estos jamás podrán exceder los barrotes de su jaula por-

${ }^{38}$ L. Cracco (1993), p. 15.

${ }^{39}$ L. Cracco (1993), p. 33.

${ }^{40}$ E. Lévinas (2012), p. 145.

${ }^{41}$ L. Cracco (1993), p. 37.

${ }^{42}$ R. Arráiz Lucca (2002), p. 375. 
que el espacio carece de ventanas, lo que reduce cualquier acto de lenguaje al grado límite de su aniquilación: la oquedad del grito que nadie escucha.

\section{Hacia nuevos paradigmas}

Concluimos este breve recorrido por la obra de estas tres autoras convencidos de la necesidad de un estudio pormenorizado de estos poemarios, pues en ellos se hallan originales interpretaciones estéticas e ideológicas que, al ser descodificadas, anuncian los cambios de rumbo de las poéticas de finales del siglo XX en Venezuela. Gracias a las nociones de alteridad y compromiso, estos testimonios podrán encauzar futuros debates acerca de nuestras certezas sobre la historia literaria, instaurando categorías alternativas de análisis que enriquezcan nuestra visión de conjunto.

Por un lado, frente a la perspectiva tradicional del compromiso encadenada a la reflexión sobre la subjetividad nacional e histórica, estas escrituras apuntan hacia la posibilidad de comprender una tipología de este fenómeno en el contexto de crisis finisecular. Así, el repliegue del sujeto sobre sí mismo y la experiencia de inéditos modos de relación se abren al conocimiento de una littérature engagée desde la singularidad del yo, y no desde la enunciación colectiva. Hablaríamos, pues, de una dinámica de reactualización del individuo que, en su vínculo con el otro, construye un sistema simbólico orientado, al igual que en la literatura escrita por hombres, hacia la universalidad, dotando al discurso de un carácter centrífugo que visibiliza todas aquellas realidades desplazadas por una lógica opresora y excluyente, desde la condición biológica de la mujer o la elección de sus prácticas sexuales hasta su desarrollo cotidiano en el espacio inhóspito de la ciudad.

Por otro lado, las características mencionadas en el desarrollo de este trabajo, en definitiva, señalan un nuevo orden de la representación como culminación de un proceso que materialmente no encuentra los cauces adecuados para su formalización, pero que, en cambio, se postula a través del arte como el deseo de un fin o, mejor aún, como el final, potencialmente feliz, de un deseo largamente sostenido. En consecuencia, los poemarios de Verónica Jaffé, Manón Kübler y Laura Cracco asumen la eventualidad de una escritura política que se opone no solo al devenir histórico, social y cultural de Venezuela, sino también a la tradición literaria que asume la voz propia bajo el signo del velo para disfrazar su naturaleza. Hastiadas de una pesada herencia, estas tres cygniformes Grayas arrancan de su rostro la máscara y arrojan al suelo siglos de expectativas sobre las que caminan, descalzas, expuestas a la herida de sus vidrios.

Si como dijo Antonio López Ortega «nunca había estado nuestra literatura tan poco comprometida consigo misma y nunca la ética del escritor había estado tan devaluada ${ }^{43}$, caigan en la cuarentena del juicio crítico estas palabras hasta que no observemos en detalle los testimonios sobresalientes de una más que robustecida eclosión femenina de las letras venezolanas.

${ }^{43}$ A. López Ortega (1995), p. 34. 


\section{OBRAS CITADAS}

ÁlVAREZ, Lázaro: «De la exaltación a la desilusión: perfiles de la poesía Venezolana», Cuadernos del Ateneo de La Laguna, 4 (1998), pp. 38-43.

ARRÁIZ LUCCA, Rafael: El coro de las voces solitarias: una historia de la poesía venezolana, Caracas, Sentido, 2002.

AUGÉ, Marc: Los «no lugares»: espacios del anonimato. Una antropología de la sobremodernidad, Barcelona, Gedisa, 1998.

CASTILlO ZAPATA, Rafael: «La otra voz: persona y personaje en cuatro poetas venezolanos de la última generación», Revista Iberoamericana, 166-167 (1994), pp. 365-380.

CrACCO, Laura: Safari Club, Caracas, Monte Ávila Editores, 1993.

FERNÁNDEZ GUERRERO, Olaya: «Sobre la alteridad y la diferencia sexual», Logos, 45 (2012), pp. 293-317.

GARMENDIA, Salvador: «La disolución del compromiso», en Karl Kohut (ed.), Literatura venezolana hoy: historia nacional y presente urbano, Madrid, Iberoamericana, 1999, pp. 23-35.

GOMES, Miguel: «Poesía transterritorial: capitalismo y "mundo imaginado" en la literatura venezolana reciente», Revista de crítica literaria latinoamericana, 58 (2003), pp. 255-273.

GONZÁLEZ STEPHAN, Beatriz: «No solo para mujeres (el sexismo en los estudios literarios)», Dispositio, 14 (1990), pp. 83-94.

HERRERA, Bernal: «Literatura política en Hispanoamérica: de las guerras culturales al compromiso ida y vuelta», en Yves Aguila e Isabelle Tauzin Castellano (ed.), Les écritures de l'engagement en Amérique Latine / Las escrituras del compromiso en América Latina, Burdeos, Presses Universitaires de Bordeaux, 2002, pp. 7-35.

JAFFÉ, Verónica: El arte de la pérdida, Caracas, Ediciones Angria, 1991.

: «Algunas anotaciones sobre la poesía contemporánea en Venezuela», en Karl Kohut (ed.), Literatura venezolana hoy: historia nacional y presente urbano, Madrid, Iberoamericana, 1999, pp. 321-332.

KÜBLER, Manón: Olympia, Caracas, Monte Ávila Editores, 1991.

LASARTE VALCÁRCEL, Javier: «Trayecto de la poesía venezolana de los ochenta: de la noche a la calle y vuelta a la noche», en Karl Kohut (ed.), Literatura venezolana hoy: historia nacional y presente urbano, Madrid, Iberoamericana, 1999, pp. 277-291.

LÉVINAS, Emmanuel: Totalidad e infinito: ensayo sobre la exterioridad, Salamanca, Sígueme, 2012.

LÓPEZ ORTEGA, Antonio: El camino de la alteridad, Caracas, Fundarte, 1995.

: «Poesía venezolana en las postrimerías del siglo XX», Galerna, 2 (2004), pp. 109-117.

MARCOTRIGIANO L., Miguel: Las voces de la hidra: la poesía venezolana de los años noventa, Mérida, CONAC, 2002. 
MIRANDA, Julio: Poesía en el espejo: estudio y antología de la nueva lírica femenina venezolana (1970-1994), Caracas, Fundarte, 1995.

MoI, Toril: Teoría literaria feminista, Madrid, Cátedra, 1988.

PACHECO, Bettina: «La escritura de las mujeres ante la crítica», en Carlos Pacheco, Luis Barrera y Beatriz González Stephan (ed.), Nación y literatura: itinerarios de la palabra escrita en la cultura venezolana, Caracas, Fundación Bigott etc., 2006, pp. 819-830.

PATIN, Yolanda: «Entrar en lo bárbaro. Una lectura de la poesía venezolana escrita por mujeres», en Karl Kohut (ed.), Literatura venezolana hoy: historia nacional y presente urbano, Madrid, Iberoamericana, 1999, pp. 305-320.

PATIN, Yolanda y TORRES, Ana Teresa (ed.): El hilo de la voz: antología crítica de escritoras venezolanas del siglo XX, Caracas, Fundación Polar, 2003.

PÉREZ LÓPEZ, Ma Ángeles: «La eclosión femenina en la poesía venezolana contemporánea. Algunas anotaciones para un mapa textual», en Javier San José Lera (ed.), Praestans labore Victor: homenaje al profesor Victor García de la Concha, Salamanca, Ediciones Universidad de Salamanca, 2005, pp. 365-382.

PRING-MiLl, Robert D. F.: «La toma de conciencia en la poesía de compromiso hispanoamericana», en Antonio Vilanova (coord.), Actas del X Congreso de la Asociación Internacional de Hispanistas (Barcelona, del 21 al 26 de agosto de 1989), Barcelona, Promociones y Publicaciones Universitarias, 1992, pp. 33-54.

ReISZ, Susana: Voces sexuadas: género y poesía en Hispanoamérica, Zaragoza, Asociación Española de Estudios Literarios Hispanoamericanos, 1996.

RICOEUR, Paul: Sí mismo como otro, Madrid, Siglo XXI, 1996.

RoDRíGUEZ, Juan Carlos: «El yo poético y las perplejidades del compromiso», Ínsula, 671-672 (2002), pp. 53-56.

RODRÍGUEZ PADRÓN, Jorge: «De poetas venezolanas y del lector que soy (pliego de descargo)», Anales de literatura hispanoamericana, 38 (2009), pp. 15-28.

RUSSOTTO, Márgara: «La amada que no era inmóvil. Identidad femenina en la poesía venezolana moderna», Nueva Sociedad, 135 (1995), pp. 150-163.

: Tópicos de retórica femenina, San José - Costa Rica, Editorial de la Universidad de Costa Rica, 2004.

ZAMBRANO, Gregory: «Las pieles de Eurídice: anotaciones sobre poesía escrita por mujeres (1970-1990)», en De historias, héroes y otras metáforas (estudios sobre literatura hispanoamericana), México D. F., Universidad Nacional Autónoma de México, 2000, pp. 87-103

: «Delta poético de las autoras venezolanas de los 90 (siglo XX)», en Gregory Zambrano (comp.), Mujer: escritura, imaginario y sociedad en América Latina, Mérida, Universidad de Los Andes, 2004, pp. 231-251. 